\title{
DỨBin
}

Technological University Dublin

ARROW@TU Dublin

2007-01-01

\section{Low-profile Rolled Planar Antenna with Wide Bandwidth}

\author{
Giuseppe Ruvio \\ Technological University Dublin \\ Max Ammann \\ Technological University Dublin, max.ammann@tudublin.ie
}

Follow this and additional works at: https://arrow.tudublin.ie/engschececon

Part of the Electrical and Computer Engineering Commons

\section{Recommended Citation}

Ruvio, G. \& Ammann, M. Low-profile rolled planar antenna with wide bandwidth. IWAT '07 International Workshop on Antenna Technology: Small and Smart Antennas Metamaterials and Applications, pp.77-80. 21-23 March, Cambridge, England, 2007, doi:10.1109/IWAT.2007.370084

This Conference Paper is brought to you for free and open access by the School of Electrical and Electronic Engineering at ARROW@TU Dublin. It has been accepted for inclusion in Conference papers by an authorized administrator of ARROW@TU Dublin. For more information, please contact arrow.admin@tudublin.ie, aisling.coyne@tudublin.ie,gerard.connolly@tudublin.ie. Funder: Science Foundation Ireland 


\title{
Low-Profile Rolled Planar Antenna with Wide Bandwidth
}

\author{
G. Ruvio and M. J. Ammann \\ Centre for Telecommunications Value-chain Research \\ School of Electronic \& Communications Engineering \\ Dublin Institute of Technology \\ Kevin Street, Dublin 8, Ireland \\ Email: giuseppe.ruvio@student.dit.ie
}

\begin{abstract}
A novel size-reduction technique for a planar monopole type antenna is presented. By rolling the planar element of this antenna, a low-profile radiator with broad impedance bandwidth is obtained without excessively perturbing its radiation properties. The proposed antenna is capable of covering frequencies in the range $3.1 \mathrm{GHz}$ to 15 GHz. The antenna yields a high gain with high radiation efficiency across the full bandwidth. Radiation patterns show good omnidirectional features, so it is a remarkable candidate for in-door or vehicular applications where large frequency range is required.
\end{abstract}

\section{INTRODUCTION}

In recent years, the design of products capable of operating across several communication protocols has attracted great interest in both the antenna industry and scientific community. One of the most important issues taken into account as a constraint for such an important target has been a sustainable compromise between compactness, decent radiation features and broad impedance bandwidth. In addition to that, a stable omnidirectional radiation pattern across the working bandwidth has been considered as an advantageous characteristic for in-door and vehicular applications. Monopolar antennas are very successful candidates to accomplish those requirements due to their large impedance bandwidth and omnidirectional patterns $[1,2]$. However, because of their bulky structure, several techniques have been recently introduced in order to reduce the overall dimension and manufacturing efforts while radiation properties are not heavily perturbed. Rolled planar monopoles have been already introduced in literature [3, 4]. This radiated element has been demonstrated to possess very interesting broadband impedance features but its long shape drastically reduces applications where more compactness is required. The antenna presented in this paper is a rolled monopolar antenna horizontally placed on the ground plane. This solution reduces the overall height of the antenna to $0.17 \lambda$ at $3 \mathrm{GHz}$. At the same time, different bandwidth enhancement techniques have been integrated. The basic idea is to exploit the impedance characteristics of a rolled monopole as seen in [3], but locating this radiating element horizontally with respect to the ground plane, so that a lower profile is achieved and that bevelling techniques can be introduced. In fact bevelling the bottom edge of planar monopolar antennas has been demonstrated to shift upward significantly the upper edge frequency $[5,6]$. A strong capacitive coupling occurs in this region and this is heavily dependent on both the bevel angle and the separation between the bottom edge of the antenna and the ground plane. A strong current distribution is concentrated in the gap between the ground plane and rolled monopole. This heavily influences the radiation properties of the antenna across the band of operation. The excitation of more modes and a consequent improvement of the impedance bandwidth response are obtained by the use of an offset feeding point. This phenomenon is well documented in literature [7]. As the antenna is folded in a roll, it assumes the shape of a cavity. This particular profile is able to separate the radiated field from the field distribution occurring within the spirals of this antenna. In fact, the impedance match of this particular planar monopole is aided by the current distribution on the roll, but its contribution to the radiated field is shielded by the bigger spiral, which shrouds the internal spirals. Numerical simulations have been obtained by Finite Integral Time Domain Method and compared to experimental results of the constructed prototype with acceptable agreement.

\section{ANTENNA DESIGN}

The antenna geometry and coordinate system is shown in Fig. 1. The planar antenna is made of $0.2 \mathrm{~mm}$ thick brass sheet rolled according to the constraints:

$$
\begin{array}{ll}
r 2=r 1-4 \mathrm{~mm} & r 3=r 1-5.5 \mathrm{~mm} \\
r 4=r 1-7 \mathrm{~mm} & r 5=r 1-8.5 \mathrm{~mm}
\end{array}
$$



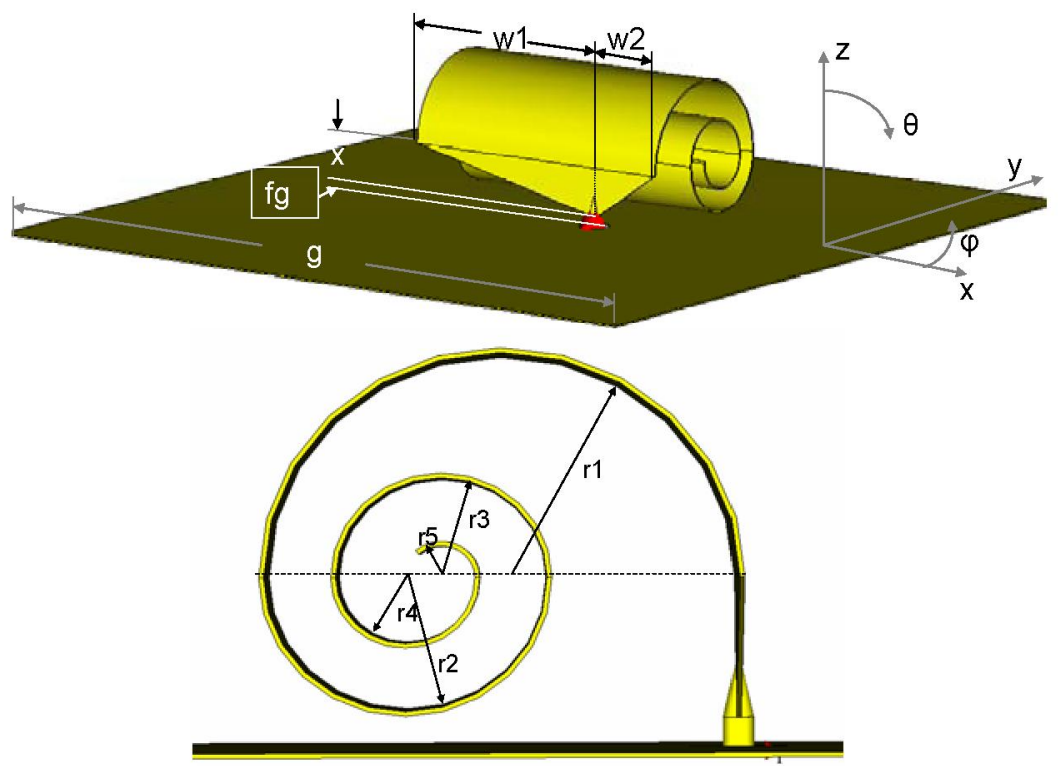

Fig.1 Geometry, coordinate system and cross-section of the antenna presented. $f g=1.3 \mathrm{~mm}, x=6.3 \mathrm{~mm}$, $g=100 \mathrm{~mm}, r l=10 \mathrm{~mm}, w 1=30 \mathrm{~mm}, w 2=9 \mathrm{~mm}$.

where $r 1$ is equal to $10 \mathrm{~mm}$. The total length of the rolled section is equal to $29.5 \pi \mathrm{mm}$. The total height of the antenna above the groundplane is given by $h=f_{g}+x+r l$. The relation between the different radii of the spires of the geometry can be kept fixed by appropriate transparent spacers. This radiating element is placed at the centre of a $100 \mathrm{x}$ $100 \mathrm{~mm}$ ground plane and the input signal is launched to the antenna through a $50 \Omega$ coaxial connector located at the back of the ground plane. The base of the radiating element is appropriately shaped to enhance the match by the insertion of a double asymmetrical bevel and an offset feed point. The optimum geometry for the double asymmetrical bevel at the base of the radiator was obtained by Finite Integral Time Domain Method, so that $W$ is given by the sum of $w 1=30 \mathrm{~mm}$ and $w 2=9 \mathrm{~mm}$. The distance $x$ from the tip of the bevelled plate to the first planar half-cylinder of radius $r 1$ is $6.3 \mathrm{~mm}$.

\section{IMPEDANCE AND RADIATION CHARACTERISTICS}

The antenna presented covers a very broad $10 \mathrm{~dB}$ Return Loss bandwidth as shown in Fig. 2. Three notches are visible at 3.7-3.9, 5.8-6.8 and $6.9-7.1 \mathrm{GHz}$ in the measurement for which the return loss does not reach $10 \mathrm{~dB}$; however, $7 \mathrm{~dB}$ is achieved from 3.1 to $15 \mathrm{GHz}$.

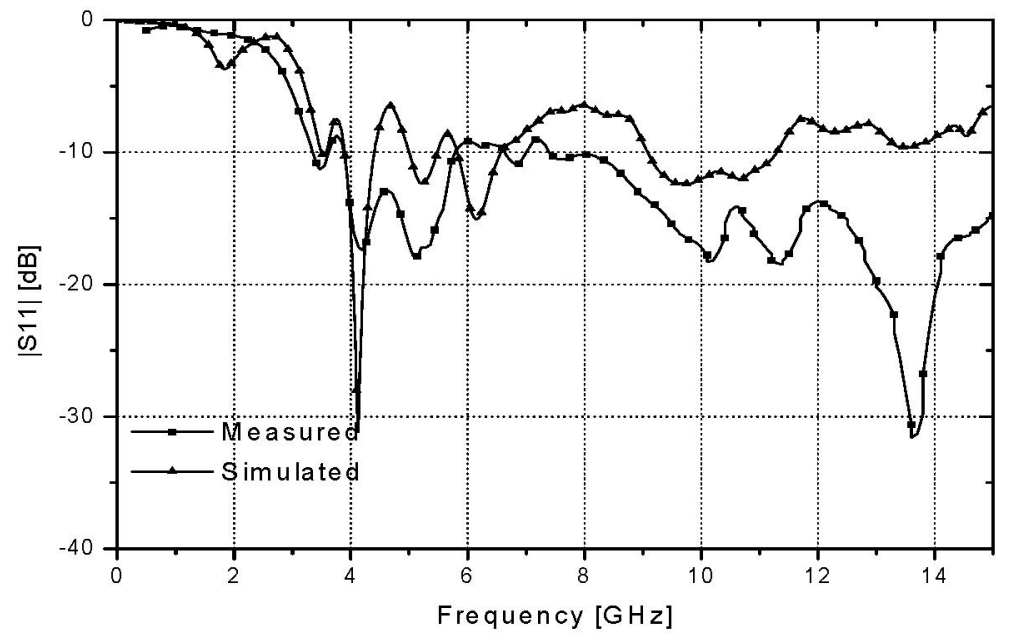

Fig. 2 Simulated and measured 10dB Return Loss Bandwidth. 

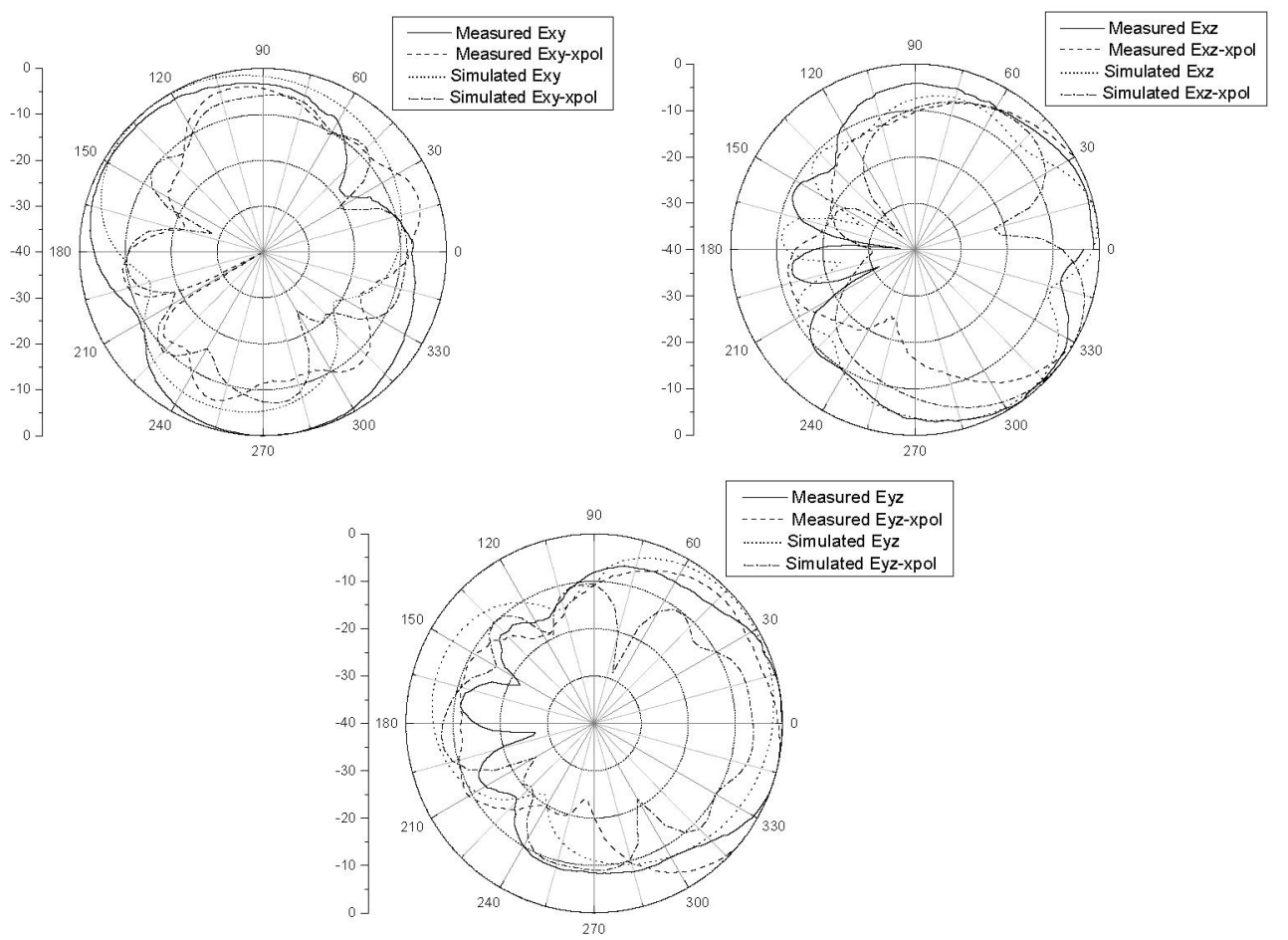

Fig. 3 Radiation patterns at 6GHz. $x y$-, $x z$ - and $y z$-cut.

A good agreement is obtained with simulations just at the lower part of the spectrum investigated. In fact, the radiating element is made of a very thin metal sheet (thickness roughly equal to $\lambda / 500$ at the lower edge frequency) rolled in three spires. Such a complex round geometry can be only generally approximated by the mesh grid. The resolution of this approximation must be carefully weighted against the computational effort. Moreover, due to its shape, the antenna is a very highly resonating structure. This makes even more difficult to reach the convergence of the algorithm within a significant threshold of accuracy and reasonable computational time. However, the package we used is still able to give an idea (although generally pessimistic) of the trend of the structure presented.

All the enhancement techniques introduced are demonstrated to be successful to stretch the impedance bandwidth of this antenna especially at the upper part of the spectrum.

The radiation pattern is illustrated in Fig. 3, which is normalised to maximum gain. The maximum gain was found to be between $7.5 \mathrm{dBi}$ and $8.5 \mathrm{dBi}$ in the broadside direction across the operative bandwidth. Three plane cuts of the radiation pattern at $6 \mathrm{GHz}$ are shown for the four configurations investigated: $\phi, \theta=90^{\circ},(x y$-plane $), \theta, \phi=0^{\circ},(x z-$ plane) and $\theta, \phi=90^{\circ}(y z$-plane) cuts. All the measured radiation patterns are illustrated against the simulated component in $10 \mathrm{~dB} /$ division scaled plots. Moreover, each radiation pattern cut is presented together with the simulated co- and cross-polar component. In particular, the $x z$-cut shows a very different behaviour when compared to a planar monopole. The monopolar null is mitigated for this structure. This suggests that the operating mode of the antenna is mainly transmission-line or patch mode [8]. This is due to the horizontal elements in radiator structure with respect to the ground plane. In fact, through simulations of the far field at low frequencies, a strong distribution of the electric field points in the $z$-axis; this is typical of a patch radiation. Also the current distribution in Fig 4 supports this thesis because the contribution to the far field of the strong current distribution in the inner spirals is limited, so that the dominant role is played by the horizontal currents on the upper part of the radiator. The offset feeding technique is employed to generate an unbalanced current on the antenna structure as shown in Fig 4. However, its does not significantly degrade the radiation pattern in the $x y$-plane, where the antenna presents good omnidirectional features. On the other hand, the $x z$-cut pattern is shown to be asymmetric as the strong $x$-component of the far field is augmented by an unbalanced current in that direction on the radiator and also reflected on the ground plane. Indeed, a maximum in the pattern is observed between $\theta=0^{\circ}$ and $\theta=30^{\circ}$ from Fig. 3 . 


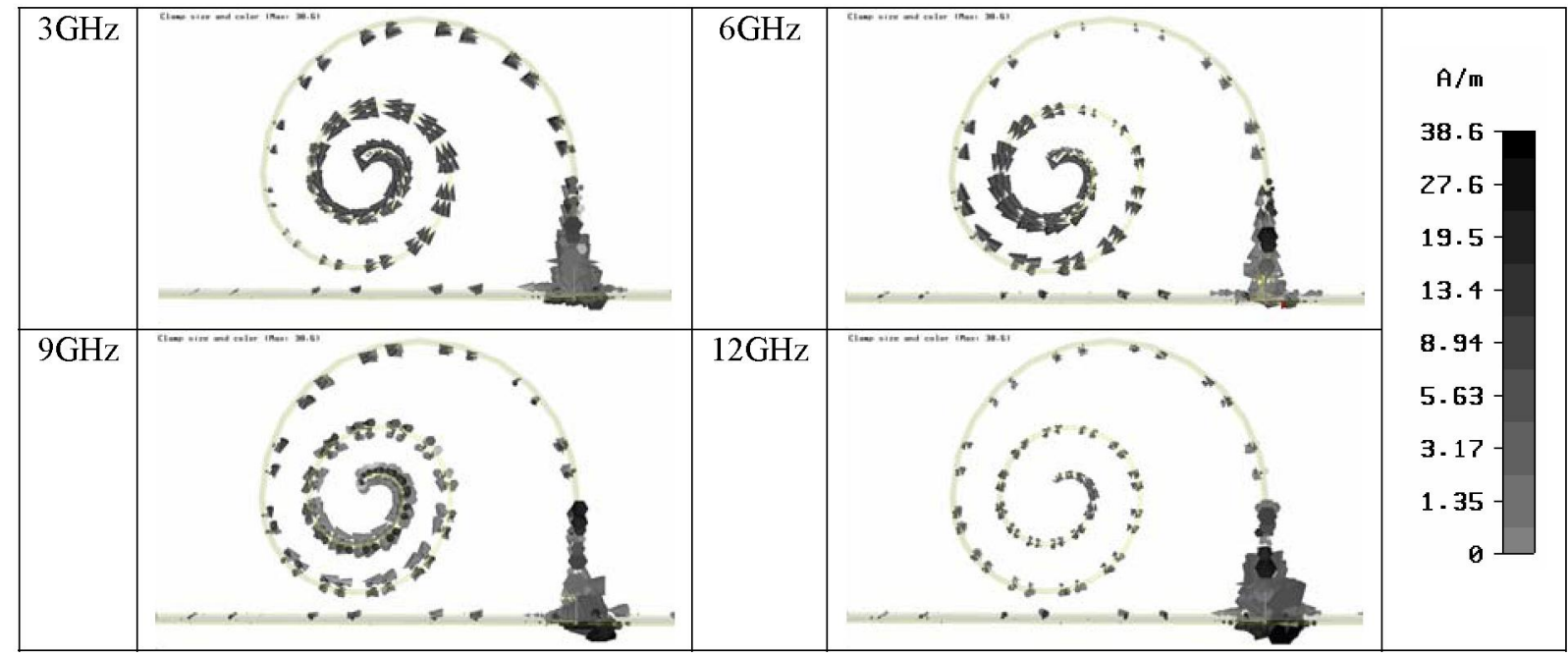

Fig. 4 Current distribution at the cross-section of the antenna.

\section{CONCLUSIONS}

A novel rolled horizontal planar monopole antenna has been presented. This radiating element presents broadband features together with interesting omnidirectional pattern. The metallic spirals that form this antenna create a constructive current distribution that improves the impedance match and reduces the overall size and profile, without heavily affecting the radiation pattern. A full investigation of the antenna has been made and a description of the broadbanding techniques has been presented. Moreover, a study of the current distribution on the structure investigated has been carried on at various frequencies within the working bandwidth. Both experimental and numerical analyses are in reasonable agreement.

\section{ACKNOWLEDGEMENTS}

This work was supported by Science Foundation Ireland.

\section{REFERENCES}

[1] N. P. Agrawall, G. Kumar and K. P. Ray, "Wide-band planar monopole antenna," IEEE Trans. Antennas and Propag., February 1998, vol. 46, no. 2, pp. 294-295.

[2] H. Kawakami and G. Sato, "Broadband characteristics of rotationally symmetric antennas and thin wire constructs," IEEE Antennas and Propag., 1987, vol. 35, pp. 26-32.

[3] Z. N. Chen, M. Y. W. Chia and M. J. Ammann, "Optimization and Comparison of Broadband Monopoles," in IEE Proc.-Microw. Antennas Propag., December 2003, vol. 150, no. 6, pp. 429-435.

[4] Z. N. Chen, "Novel Bi-Arm Rolled Monopole for UWB Applications," IEEE Trans. Antenna and Propag., February 2005, vol. 53, no. 2, pp. 672-677.

[5] M. J. Ammann, "Control of the impedance bandwidth of wideband planar monopole antennas using a beveling technique," Microw. Opt. Techn. Letters, July 2001, vol. 30, no. 4, pp. 229-232.

[6] M. J. Ammann and Z. N. Chen, "A Wide-Band Shorted Planar Monopole With Bevel," IEEE Trans. Antennas and Propag., April 2003, vol. 51, no. 5, pp. 901-903.

[7] M. J. Ammann and Z. N. Chen, "An asymmetrical feed arrangement for improved impedance bandwidth of planar monopole antennas," Microw. Opt. Techn. Letters, 2004, vol. 40, no. 2, pp. 156-158.

[8] M. J. Ammann and Z. N. Chen, "Investigation on L-shaped Planar Antennas," Radio Science, April 2004, vol. 39 , no. 2 , art. no. RS2009. 